\title{
Closing the gap: the potential of Christian Health Associations in expanding access to family planning
}

\author{
Lauren VanEnk ${ }^{a}$, Ronald Kasyaba ${ }^{b}$, Prince Bosco Kananic, Tonny Tumwesigye ${ }^{d}$, and \\ Jeannette Cachan ${ }^{\mathrm{e}}$ \\ ${ }^{a}$ MPH, Program Officer, Institute for Reproductive Health, Georgetown University, USA \\ ${ }^{\mathrm{b}} \mathrm{MD}$, Assistant Executive Secretary, Uganda Catholic Medical Bureau, Uganda \\ 'MD, MHCDS, Director, Caritas Rwanda Catholic Health Services, Rwanda \\ ${ }^{d}$ MD, MPH, Executive Director, Uganda Protestant Medical Bureau \\ e MA, M.Ed, Director of Capacity Building and Technical Assistance, Institute for Reproductive Health, Georgetown \\ University, USA
}

\section{Abstract}

Recognizing the health impact of timing and spacing pregnancies, the Sustainable Development Goals call for increased access to family planning globally. While faith-based organizations in Africa provide a significant proportion of health services, family planning service delivery has been limited. This evaluation seeks to assess the effectiveness of implementing a systems approach in strengthening the capacity of Christian Health Associations to provide family planning and increase uptake in their communities.

From January 2014 to September 2015, the capacity of three Christian Health Associations in East Africa-Caritas Rwanda, Uganda Catholic Medical Bureau, and Uganda Protestant Medical Bureau-was strengthened with the aims of improving access to women with unmet need and harmonizing faith-based service delivery contributions with their national family planning programs. The key components of this systems approach to family planning included training, supervision, commodity availability, family planning promotion, data collection, and creating a supportive environment. Community-based provision of family planning, including fertility awareness methods, was introduced across intervention sites for the first time. Five hundred forty-seven facility- and community-based providers were trained in family planning, and 393,964 people were reached with family planning information. Uptake of family planning grew substantially in Year $1(12,691)$ and Year $2(19,485)$ across all Christian Health Associations as compared to the baseline year $(3,551)$. Cumulatively, 32,176 clients took up a method during the intervention, and 43 percent of clients received this service at the community level. According to a provider competency checklist, facility- and community-based providers were able to adequately counsel clients on new fertility awareness methods. Integration of Christian Health Associations into the national family planning strategy improved through participation in routine technical working group meetings, and the Ministries of Health in Rwanda and Uganda recognized them as credible family planning partners. Findings suggest that by strengthening capacity using a systems approach, Christian Health Associations can meaningfully contribute to national and international family planning goals. Increased attention to community-based family planning provision and to mainstreaming family planning service delivery across Christian Health Associations is recommended. 


\section{Introduction}

Preventing unintended pregnancies could save the lives of more than 2 million infants and children annually worldwide, and could significantly reduce maternal mortality and morbidity. ${ }^{1}$ This positive impact on health outcomes, among other benefits, is why increased access to family planning information and education is one of the Sustainable Development Goals set by the international community. ${ }^{2}$

Modern family planning use among women with unmet need is lowest in sub-Saharan Africa. ${ }^{3}$ Meeting this need remains a challenge. While faithbased organizations represent 20-50 percent of the national health sector across a number of African countries, ${ }^{4}$ their contribution to family planning service delivery is significantly less than other health services offered by these facilities. ${ }^{5,6}$

Even in light of the life-saving evidence supporting healthy timing and spacing of pregnancies, faithbased organizations have found including family planning in their programming to be challenging due to a lack of capacity or the belief that specific family planning methods are at odds with their religious tenets. ${ }^{7}{ }^{8}$ Even in the midst of partnerships between faith-based and non-religious development organizations, there is a concern that religious ideologies may overtake empirical evidence in delivering information and services or, on the other hand, that core religious values may be compromised along the way. ${ }^{9}$

With their broad networks and sustained presence, faith-based organizations have the potential to increase the demand for and use of health services, and significantly contribute to achieving the Sustainable Development Goals. ${ }^{10}$ Faith is an important determinant of value systems at both the individual and community levels. ${ }^{11}$ Nearly nine in ten Africans identify themselves as Christian or Muslim, and 69-98 percent describe religion as "very important" in their lives. ${ }^{12}$ Often the largest non-governmental healthcare providers in African countries are faithbased organizations. In many countries, Christian Health Associations (CHAs) coordinate with faithbased health facilities (Table 1) ${ }^{13}$ CHAs often work closely with ministries of health through established memoranda of understanding to complement public sector service delivery. Their engagement in family planning, however, is limited, especially among Catholic health networks. The structures are in place for CHAs to contribute to national reproductive health strategies, but lack of capacity along with unavailability of appropriate family planning methods have kept them from broader participation. ${ }^{7}$

Given the vital role of CHAs in healthcare delivery, there has been an increase in engagement with international aid agencies prompting an exploration of the ways that religion may promote family planning. Based on the interest among CHAs to offer family planning services, this intervention seeks to strengthen their programs using a systems approach and better aligns their service delivery with national strategies in Rwanda and Uganda.

Table 1. Christian Health Associations in Rwanda \& Uganda

Rwanda: Caritas Rwanda is a network of Catholic hospitals and clinics that operates around 30 percent of health facilities nationally and has an established memorandum of understanding with the Ministry of Health. Some staff within Caritas Rwanda facilities are seconded from the Ministry of Health, and data (including family planning) is expected to be reported through the national health management information system (HMIS) in the same way as public facilities.

Uganda: The private-not-for-profit health sector is primarily made up of four faith-based organizations Uganda Catholic Medical Bureau, Uganda Protestant Medical Bureau, Uganda Muslim Medical Bureau, and Uganda Orthodox Medical Bureau. Together they account for 35 percent of health services and training institutions in the country. They each have established memoranda of understanding with the Ugandan government, and they often collaborate as a unified consortium. Some staff within these private-notfor-profit facilities are seconded from the Ministry of Health, and data (including family planning) is expected to be reported through the national HMIS in the same way as public facilities. 


\section{Intervention description}

From January 2014 to September 2015, a systems approach was used to strengthen the family planning capacity of three CHAs in Rwanda and Uganda: Caritas Rwanda, Uganda Catholic Medical Bureau (UCMB), and Uganda Protestant Medical Bureau (UPMB). This systems approach targeted the fundamental building blocks of family planning programs: training, supervision, commodity availability, family planning promotion, data collection, and creating a supportive environment (Figure 1). The approach was tailored to the local context of each CHA to ensure acceptability within their religious tradition. For example, Caritas Rwanda and UCMB are Catholic organizations and offered only natural methods of family planning. Fertility awareness methods (FAMs) - Standard Days Method $^{\mathbb{}}$ (SDM) used with the visual aid CycleBeads ${ }^{\circledR}$, TwoDay Method $^{\circledR}$, and Lactational Amenorrhea Method (LAM) - were introduced at the facility and community levels, which allowed these CHAs to provide a range of modern and effective options that were consistent with their faith (Table 2). For UPMB, capacity was strengthened across all modern methods in addition to expanding the method mix with new fertility awareness methods.

Figure 1. A systems approach to family planning programs

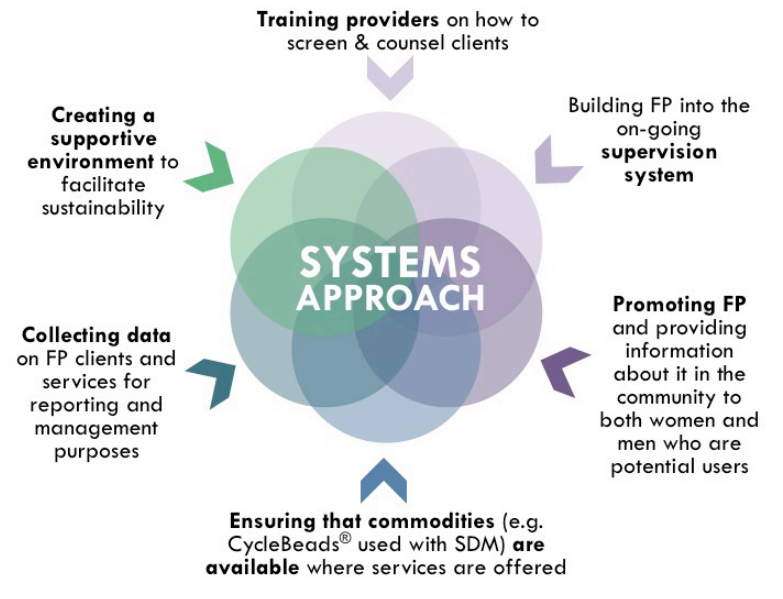

Table 2. Fertility awareness methods of family planning

Fertility awareness methods are natural methods of family planning that are classified as modern methods by the World Health Organization, FP2020, USAID, and other international organizations. The fertility awareness methods included in this intervention were:

Standard Days Method ${ }^{\circledR}$ (SDM) identifies a fixed set of days in each menstrual cycle when a woman can get pregnant if she has unprotected intercourse. If the woman does not want to get pregnant, she and her partner avoid unprotected intercourse on days 8 through 19 of her cycle. A woman can use CycleBeads $^{\circledR}$, a color-coded string of beads, to help track the days of her menstrual cycle and see which days she is most likely to get pregnant. SDM is 95 percent effective with correct use and 88 percent effective with typical use. ${ }^{14}$

TwoDay Method ${ }^{\circledR}$ is a fertility awareness method of family planning that uses cervical secretions to indicate fertility. A woman who uses the TwoDay Method $^{\circledR}$ checks for cervical secretions at least twice a day. If she notices secretions of any type, color, or consistency either "today" or "yesterday," she considers herself fertile. TwoDay Method ${ }^{\circledR}$ is 96 percent effective with correct use and 86 percent effective with typical use. ${ }^{15}$

Lactational Amenorrhea Method (LAM) is a shortterm family planning method based on the natural effect of breastfeeding on fertility. The act of breastfeeding, particularly exclusive breastfeeding, suppresses the release of hormones that are necessary for ovulation. If the following conditions are met, the method provides protection from pregnancy:

1. the mother's monthly bleeding has not returned since her baby was born, AND

2. the baby is only/exclusively breastfed (day and night), AND

3. the baby is less than 6 months old.

LAM is 99 percent effective with correct use and 98 percent effective with typical use. ${ }^{16}$ 
Each of the system components was addressed in the following manner:

\section{Training providers}

Facility- and community-based providers were trained to offer family planning in 51 sites, and an additional 31 UCMB sites (primarily health posts) received training for facility-based providers only. Community-based family planning was new across all intervention sites, and the profile of these community health workers (CHW) included community volunteers, Village Health Teams, catechists, and expert couples. The training curriculum was designed using guidance documents such as the WHO Medical Eligibility Criteria and the national family planning curricula. Caritas Rwanda and UCMB equipped their providers to offer fertility awareness methods that were consistent with Catholic teaching, and directed clients to a nearby facility or secondary post (Rwanda) if they wished to use a method not offered by the site. UPMB providers received a contraceptive technology update on all methods available in Uganda in addition to the new fertility awareness methods. CHWs from UPMB were trained to offer pills, condoms, and fertility awareness methods as well as referrals to the facility for other family planning options.

\section{Supervision system}

Family planning was integrated into the supervision systems at intervention sites. Focal persons were identified and trained to conduct supportive supervision with facility- and community-based providers. Through monthly meetings with CHWs, supervisors helped address challenges, ensured routine reporting of data, and coordinated resupply of commodities. Supervision was also conducted by central level managers to assess progress on each component of the systems approach.

\section{Promoting family planning}

The availability of new methods and new community-based services provided the opportunity to revitalize family planning outreach in the facility and the community. The CHAs produced radio spots and promotional materials to raise awareness of family planning. At the facilities, information was given in waiting rooms of various wards, particularly while women waited for pre-, ante-, and post-natal services. CHWs raised awareness by conducting health information sessions in their villages with women's groups, churches, crowds during market days, etc. Additionally, UPMB equipped religious leaders from a variety of faith perspectives (Protestant, Catholic, and Muslim) with knowledge about the benefits of family planning, and the importance of healthy timing and spacing of pregnancies. Emphasis was placed on dispelling myths, sharing information about service availability, and creating linkages with the new cadre of CHWs in their area.

\section{Commodity availability}

CHAs supported intervention sites to improve their forecasting, procurement, and management of family planning commodities during supervision visits. In Uganda, fertility awareness methods were not offered in most health facilities, and CycleBeads ${ }^{\circledR}$ were not procured nationally. Therefore, UPMB and UCMB managed a separate supply chain to ensure stock of CycleBeads ${ }^{\circledR}$ at intervention sites.

\section{Collecting data}

Since family planning at the community level was a new service for these CHAs, a reporting structure was developed to facilitate the flow of data from the field. Although facilities were recording family planning service statistics, the reports were not being transferred to the Ministry of Health through the health management information system (HMIS). Data managers and providers were then supported through supervision to ensure that family planning service delivery data from CHAs reached the district level.

\section{Creating a supportive environment}

To be seen as credible partners in family planning, it was essential for CHAs to participate in their national strategy dialogue. Under the intervention, CHAs briefed and regularly updated policymakers, program managers, and influential family planning practitioners about their activities as new experiences and findings emerged. They advocated with stakeholders for inclusion of their activities, including FAM, into national norms and program 
guidelines, the national HMIS, and commodity procurement mechanisms.

\section{Program Evaluation Methods}

This evaluation sought to assess the effectiveness of implementing a systems approach in strengthening the capacity of CHA sites to provide family planning at the facility and community level and, ultimately, increase uptake of family planning. The intervention was evaluated using program data from family planning service statistics, program reports, competency checklists with providers (Knowledge Improvement Tool - KIT), and qualitative interviews with providers.

Service statistics: Routine service statistics documenting family planning uptake were collected on a monthly basis from intervention sites. Baseline service statistics from 2013 (year preceding intervention activities) were compared with services statistics from 2014 (Year 1) and 2015 (Year 2) to assess the impact of the intervention on overall uptake by method and type of provider.

Program reports: The majority of monitoring and evaluation data was collected via routine program reports including awareness-raising activity reports, meeting reports, supervision reports, and quarterly reports.

Knowledge Improvement Tool (KIT): The KIT assesses provider competency in screening for and offering family planning methods. The KIT was implemented periodically, beginning at least three months after initial provider training. Supervisors administered the KIT to a convenience sample of 172 providers through a counseling role-play and scored providers on the key messages included during counseling. Scores were calculated by percent of key counseling aspects covered correctly, and aggregated to show trends across providers from different sites and levels.

Provider interviews: In-depth interviews and focus group discussions were conducted with focal persons and providers at the facility and community level. Interview discussion guides included questions on experiences offering family planning, and perceptions of acceptability and feasibility of the intervention. In total, 88 providers were interviewed: 18 facility-based providers and 70 CHWs. The interviews were conducted in the local language spoken by providers, and they were recorded, transcribed, and translated into English for analysis.

\section{Findings}

\section{Programmatic capacity building}

The following results demonstrate the change in programmatic capacity according to the systems approach.

Provider training and supervision: One hundred sixty-one facility providers and 386 CHWs were trained to offer family planning (Table 3 ). Providers were generally satisfied with the family planning training they received and expressed confidence in their knowledge and skills, particularly related to fertility awareness methods. Several went on to become users of the methods themselves.

The training was good and it has helped very many clients learn that family planning exists, and it is very effective if used in an effective way. (Facility-based provider, UCMB)

After the training, I was equipped and able to discern who should use the methods through the use of the screening guides, and, above all, I would not turn away clients who asked for other methods that I couldn't provide. [I sent them] to

Table 3. Number of providers trained in family planning by level and $\mathrm{CHA}$

\begin{tabular}{|c|c|c|c|}
\hline & $\begin{array}{c}\text { Facility- } \\
\text { based }\end{array}$ & $\begin{array}{c}\text { Community- } \\
\text { based }\end{array}$ & Total \\
\hline $\begin{array}{c}\text { Caritas Rwanda } \\
\text { Sites=40 }\end{array}$ & 40 & 200 & 240 \\
\hline $\begin{array}{c}\text { UPMB } \\
\text { Sites=8 }\end{array}$ & 31 & 84 & 115 \\
\hline $\begin{array}{c}\text { UCMB } \\
\text { Sites=34 }\end{array}$ & 90 & 102 & 192 \\
\hline Total & 161 & 386 & 547 \\
\hline
\end{tabular}


get both injectable and implants of their choice. (CHW, UPMB)

I am now very experienced. If I meet anyone in the village and they ask me about family planning, I can easily respond and give clear information. Secondly, I am respected and besides, I have become a very good example of a satisfied user of a natural family planning method. I have used it to space my children very well. (CHW, UPMB)

Of the original 547 providers who were trained, the counseling capacity of 172 providers offering fertility awareness methods was measured using the KIT. Figure 2 shows the average provider scores for each method, site, and provider level. Facility providers generally scored higher than CHWs

Figure 2. Percent of key counseling messages correctly administered using KIT for provider competency by method for facility and community-based providers
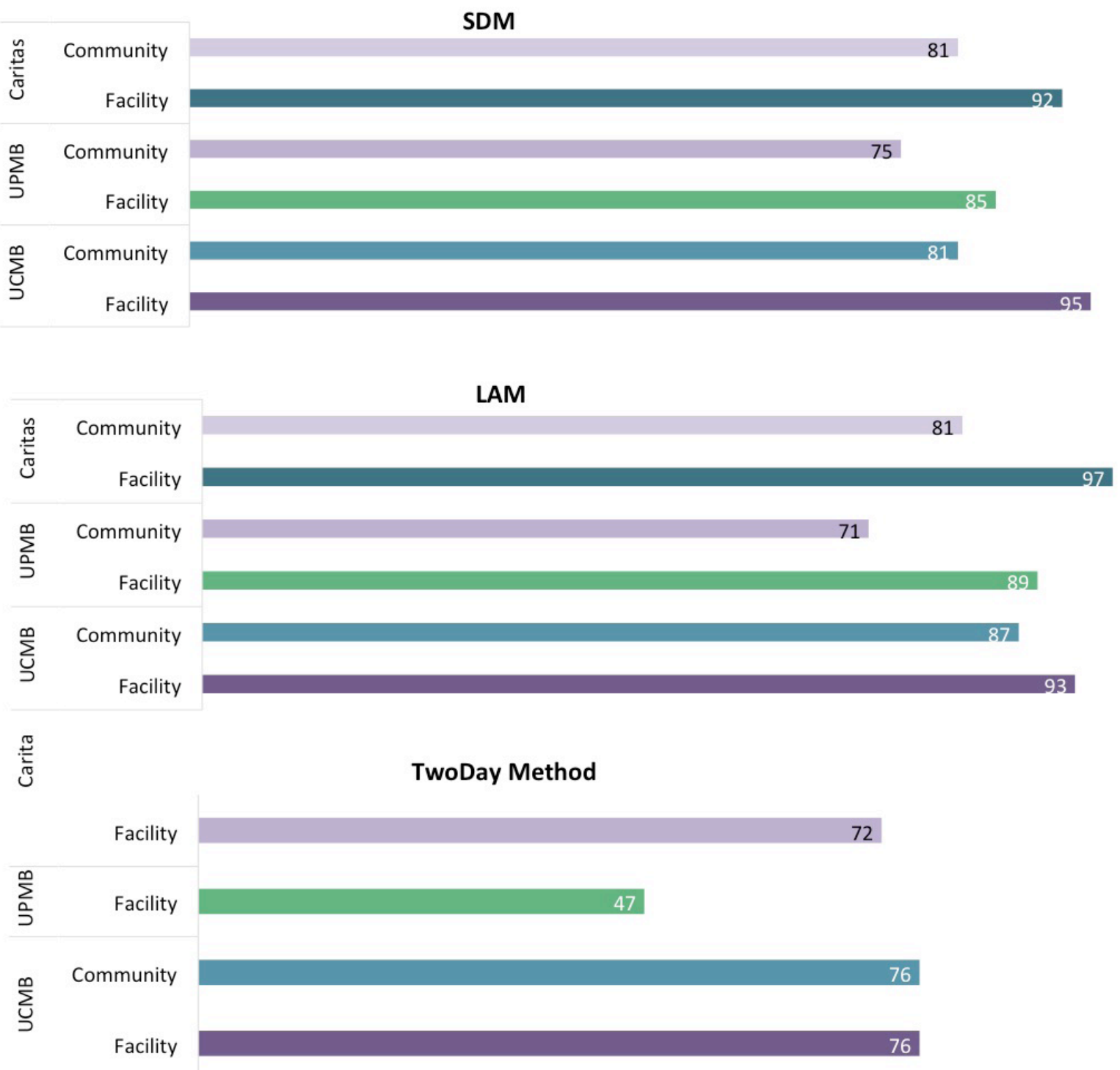
across all methods and sites. Scores for SDM and LAM were consistently higher than scores for the TwoDay Method ${ }^{\circledR}$. Providers from UCMB and Caritas Rwanda (Catholic organizations that offered only natural methods) had higher scores than providers from UPMB (which offered the full range of methods).

Promoting family planning: From July 2014 September 2015, providers from all intervention sites Table 4. Number of awareness- and 83 religious raising events and people reached with family planning information

\begin{tabular}{|c|c|c|}
\hline & Events & $\begin{array}{c}\text { People } \\
\text { reached }\end{array}$ \\
\hline $\begin{array}{c}\text { Caritas } \\
\text { Rwanda }\end{array}$ & 15,747 & 237,446 \\
\hline UPMB & 7209 & 98,054 \\
\hline UCMB & 1379 & 58,464 \\
\hline Total & 24,335 & 393,964 \\
\hline
\end{tabular}
leaders trained by UPMB were able to conduct a total of 24,335 awareness-raising events and reach an estimated 393,964 community members with information about family planning (Table 4).

Data collection: In many sites, challenges were identified with reporting data. Family planning service statistics were collected in provider registers but were not often transferred into monthly HMIS reports sent to the Ministry of Health. Furthermore, HMIS reports in Rwanda and Uganda did not allow disaggregation of certain methods, including SDM, TwoDay Method $^{\circledR}$, and LAM. Through targeted supervision, facilities began regularly sending family planning reports to the district allowing for the contribution of CHAs to be included in national level results. In particular, Catholic health facilities were now able to include family planning service data in monthly reports to the government where they previously reported nothing. However, reporting was a challenge experienced by all intervention sites. Focal persons struggled to integrate CHW services into the facility register on a regular basis, and monthly HMIS reports to the government required improvement.

Previously, they were not reporting anything on the natural family planning services to the govern- ment, but now it is being included in the data to the government. (Facility-based provider, UCMB)

I agree that we did not document properly. We would provide family planning, fill the monthly reporting form and the other gathering information tool, but we would not fill in the registers. So, a follow-up team from UPMB came and showed us how we were to do it. They helped us, and again another group came at the beginning of this year with the community reports. The community reports were not being attached to HMIS forms, so we corrected that. The community VHT reports, we now sum it up and send to HMIS. (Facility-provider, UPMB)

Partners have advocated with the Ministry of Health in Uganda to improve accuracy of the HMIS form, ensuring that the full range of methods are included. The ministry recognized this need and will consider incorporating them during the next round of HMIS form revisions.

Commodity Availability: One of the biggest challenges for program sustainability in Uganda was the difficulty of obtaining CycleBeads ${ }^{\circledR}$, which could not be procured alongside other family planning commodities. Using a donation of CycleBeads ${ }^{\circledR}$ from the Institute for Reproductive Health, UCMB and UPMB self-managed facility stock levels using a parallel supply chain, which created an additional burden for the management teams. Through advocacy with the Ministry of Health, CycleBeads ${ }^{\circledR}$ have been integrated into the Costed Implementation Plan in Uganda, though procurement has not yet moved forward.

Creating a Supportive Environment: To further collaborate with the Ministry of Health, Caritas Rwanda and UCMB joined the Family Planning Technical Working Groups in Rwanda and Uganda for the first time, and UPMB strengthened its existing involvement with them. These are committees hosted by the Ministry of Health to coordinate all family planning efforts nationally. As a result, they were recognized as partners supporting national family planning goals. The Ministry of Health in Uganda requested support from UCMB to lead 
development of the fertility awareness method modules in the revised national training curriculum. The Ministry of Health also appreciated the active engagement of religious leaders in the community as they were influential role models but often perceived as barriers to family planning uptake. Both UCMB and UPMB have been acknowledged by the Ministry of Health for their efforts to involve men in family planning services and decision-making.

\section{Family planning uptake}

A total of 32,176 clients accepted a method after receiving counseling from a trained provider at an intervention site between Jan. 2014 and Dec. 2015 (Figure 3). Uptake of family planning grew substantially in Year $1(12,691)$ and Year $2(19,485)$ of the intervention as compared to the baseline year $(3,551)$. CHWs contributed substantially to this increase, with 43 percent of new family planning clients receiving counseling at the community level (Figure 4).

Family planning uptake across UPMB sites grew by 138 percent from baseline to Year 1 and then by 22 percent from Year 1 to Year 2. Uptake across Caritas Rwanda sites grew by 259 percent from the baseline year to Year 1 and increased another 29 percent from Year 1 to Year 2. Baseline uptake for UCMB is Dec. 2015
Figure 3. Family planning uptake by quarter between Jan. 2014 -

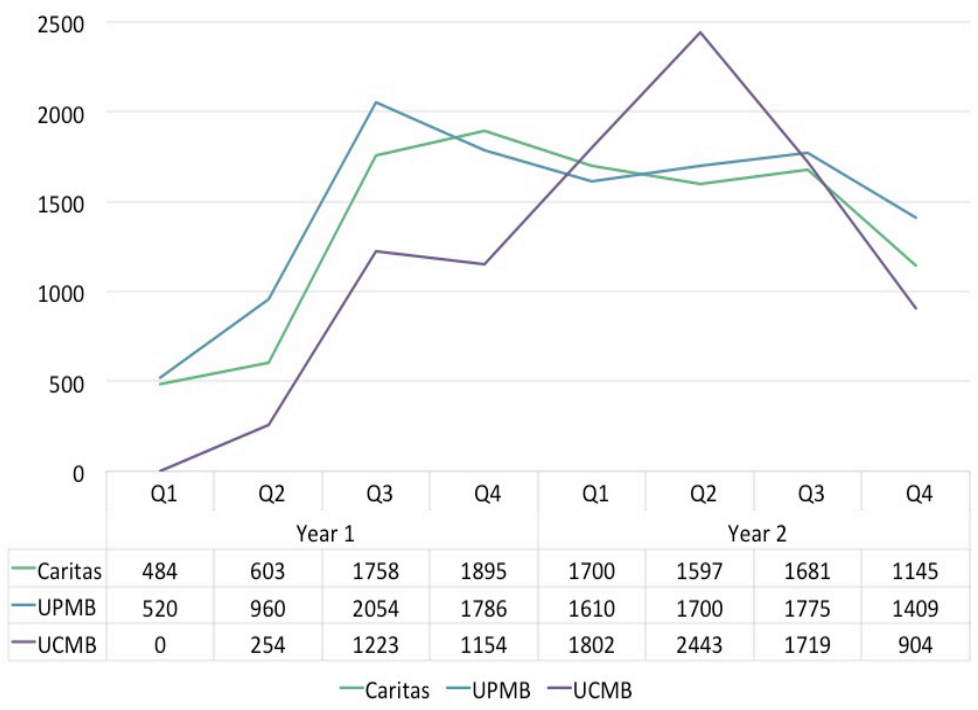

assumed to be zero since their facilities had no functioning family planning program. From intervention Year 1 to Year 2, uptake increased by 161 percent.

Family planning use increased for all methods offered by UPMB sites except female and male sterilization (Figure 5). Uptake of methods newly available at the community level substantially increased (pills, SDM, LAM, and TwoDay Method ${ }^{\circledR}$ ). The most frequently provided method was SDM, followed by injectable and implant. For both UCMB and Caritas, the most frequently provided method was LAM, followed by SDM (Figures $6 \& 7$ ).

Figure 4. Comparison of family planning uptake at the facility and community level at baseline (2013), Year 1 (2014), and Year 2 (2015) of the intervention. Caritas Rwanda and UCMB uptake data include only natural methods. UPMB uptake data include all methods.

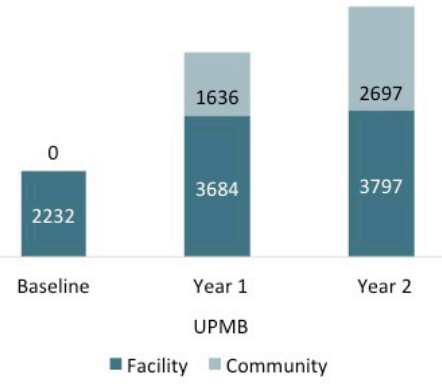

60 | Christian Journal for Global Health 4(2) 
Figure 5. UPMB family planning uptake by method at baseline (2013), Year 1 (2014), and Year 2 (2015)

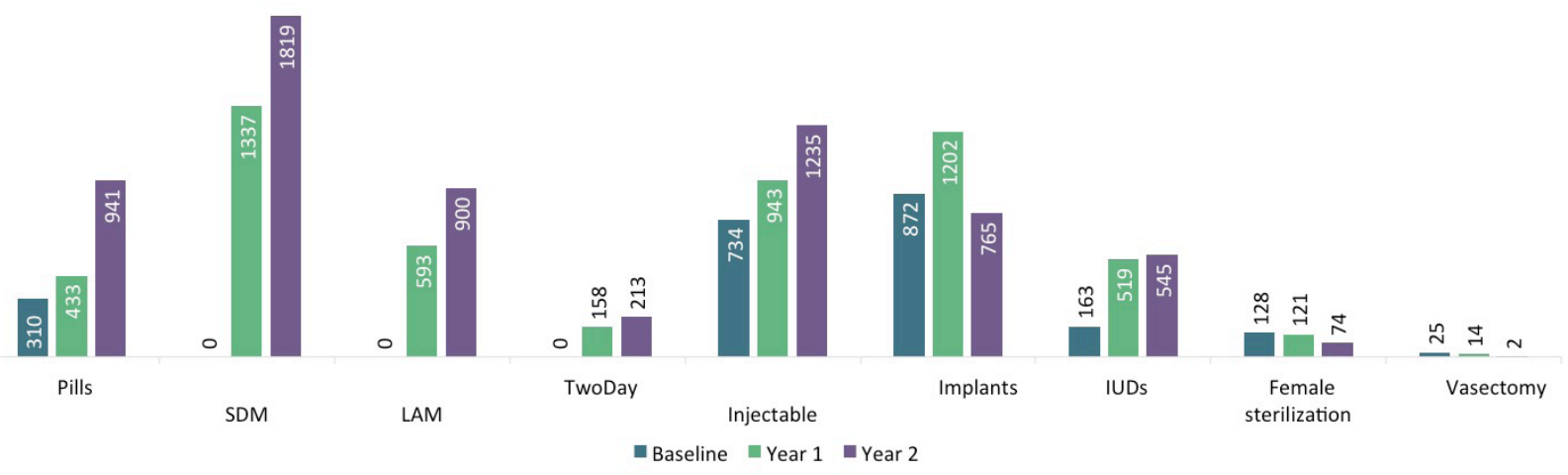

Figure 6. UCMB family planning uptake by method at Year 1 (2014), and Year 2 (2015)

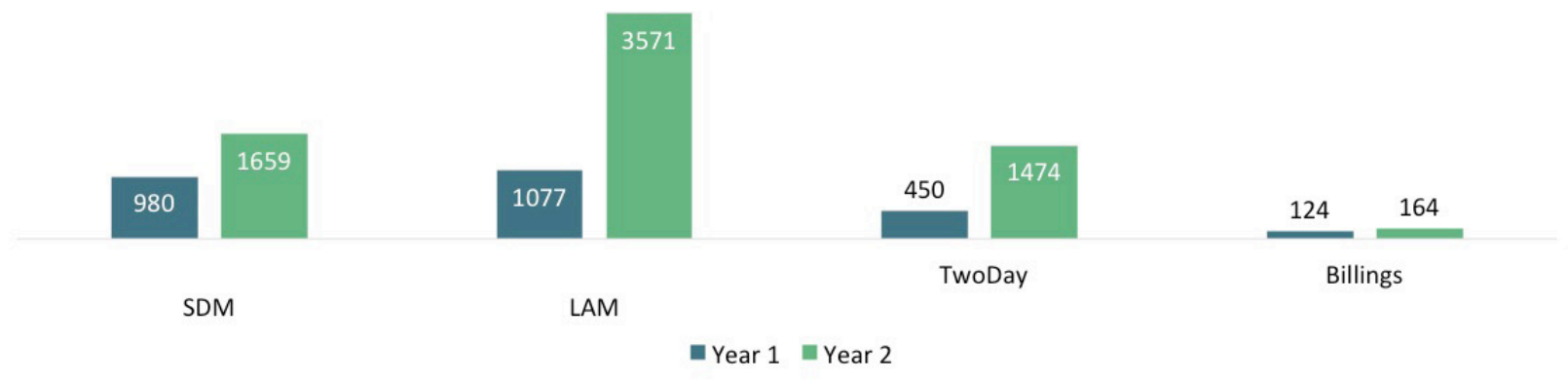

Figure 7. Caritas Rwanda family planning uptake by method at baseline (2013), Year 1 (2014), and Year 2 (2015)

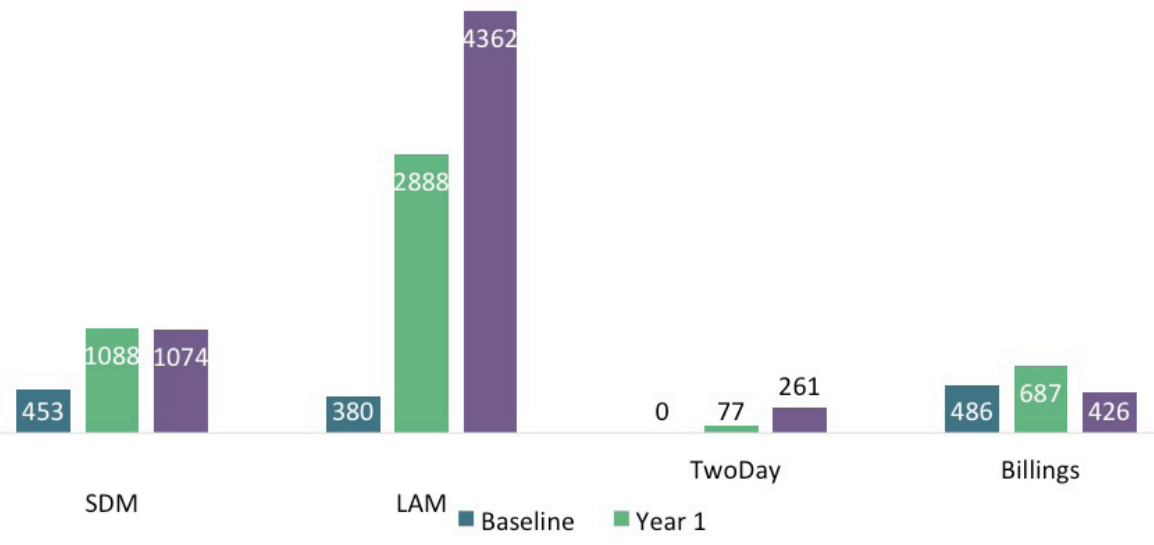

According to interviews with providers, there was clients were interested in these options was their a demand for fertility awareness methods among lack of side effects.

clients, both men and women. The primary reason 
The number of clients coming to access the service at the facility is increasing. When you teach a group, they tell others and they send them here. (Facility-based provider, UCMB)

People like those methods and say that they are good because they do not have side effects. (CHW, Caritas Rwanda)

When they announce in the church that after the mass those who want natural family planning will meet with the provider, men attend counseling sessions. Moreover, men come when we invite them to attend counseling sessions here at the health center. (Facility-based provider, Caritas Rwanda)

\section{Discussion}

The program evaluation results point to a significant increase in family planning uptake among potential clients when CHAs use a systems approach to program strengthening. These findings demonstrate that faith-based health networks have the potential to meaningfully contribute to family planning outcomes, and they are willing and able to do so with capacity strengthening.

Across all intervention sites, uptake of family planning grew significantly and quickly when comparing baseline service statistics to service delivery during the intervention. Providers and religious leaders were active in awareness-raising and reached nearly 400,000 men and women with family planning information. Clients from UCMB and Caritas Rwanda most frequently opted for LAM, likely due to efforts that CHAs made in integrating family planning into pre-, ante-, and post-natal health services at the facility. This was a critical time for women and couples to receive family planning information and counseling as data globally revealed a large unmet need among postpartum women. While providers actively followed up with LAM users to support their transition to another family planning method, data on the total number of women who succeeded in transition was not available.

62 | Christian Journal for Global Health 4(2)
Clients from UPMB most frequently opted for SDM, followed by injectable and implant. This finding contrasted with overall rates of method use in Uganda where rates of SDM use were low. However, it is important to recognize that availability of fertility awareness methods in Uganda was low even though the methods were included in the national family planning norms. In reality, providers were not trained to offer any fertility awareness methods, and CycleBeads ${ }^{\circledR}$ were not available in the majority of facilities across the country. Fertility awareness methods were also not generally included in awareness-raising messages, so the community knew very little about their effectiveness and availability. With the information, skills, and commodities from this intervention, SDM became a viable part of the method mix. Furthermore, it was available for the first time at the community level, which made access easy and cost-effective.

Even though SDM was the most popular among UPMB clients, uptake across other methods continued to increase during the intervention. Exceptions were a minimal decrease in male and female sterilization (which were already low) and a decrease in implant use during the second year of the intervention. This was most likely due to the closing of a separate program intervention that had focused on improving access to the implant in several shared sites.

Competency scores from FAM counseling indicate that the majority of providers scored 75 percent or above across the three methods, which suggests adequate service provision. Providers consistently scored the lowest on the TwoDay Method ${ }^{\circledR}$, which could be attributed to a number of factors including fewer opportunities for counseling practice due to the smaller number of clients opting for this method and apprehension about women monitoring signs of fertility like cervical secretions. Scores among UPMB providers were consistently lower than scores for providers of a similar profile at Caritas Rwanda and UCMB. Since UPMB provided the full range of methods, there were fewer opportunities for providers to practice counseling clients in FAM. Similarly, providers at Caritas Rwanda and UCMB 
received more focused mentorship on FAM during supervision visits because they did not offer the full range of methods like providers at UPMB. This indicates the important role of supportive supervision across all programs, regardless of method mix. Catholic health networks, in particular, have a wide reach in many African countries, but they provide few to no family planning services. The experience of UCMB and Caritas Rwanda reveal that offering modern fertility awareness methods presents a culturally appropriate way to contribute to national and international family planning goals. Where UCMB facilities were providing very limited family planning services before, they are now able to offer multiple options. Providers across UCMB's network have shown an enthusiasm about offering these services, and the increase in use of these methods signals that clients also have a demand for natural options. A demand for fertility awareness methods was also seen across UPMB sites and has been previously documented in Muslim populations ${ }^{17,18}$ signaling broad acceptability across faith communities.

While CHAs are meeting this demand for natural methods, their contribution is not often reflected in national level statistics because the HMIS does not include these methods. Moreover, contraceptive forecasting relies on accurate user data from facilities as this represents demand for each method. In the case of FAM, accurate user data through HMIS reports is essential to advocate for CycleBeads ${ }^{\circledR}$ inclusion in national procurement tables and integration of fertility awareness methods as part of the method mix.

Data reveal that one-third to one-half of clients received their method from a $\mathrm{CHW}$, signaling the importance of bringing family planning services closer to the user. UPMB and Caritas Rwanda had previously offered family planning services only at the facility level. During the intervention, they saw the biggest impact from the expansion of family planning at the community level. Competency scores and provider interviews confirm that CHWs are able and willing to offer family planning to their community, and they perceive it to be consis- tent with their religious beliefs. Many CHAs have community health programs but are not currently offering family planning methods at the community level due to lack of funding and capacity. Therefore, support is needed to integrate family planning into the services already being provided by CHWs.

By and large, advancements were made toward integration of CHA family planning service delivery into the national strategy. However, without a strategic investment in capacity building among CHAs, their family planning contribution is likely to remain minimal. Family planning reporting tends to be weak across both public and CHA facilities, and parallel reporting structures often exist among CHAs. Considering the challenges of harmonizing reporting structures with the Ministry of Health and the absence of fertility awareness methods in the HMIS, one can assume that the contribution of Christian Health Associations is underrepresented. By strengthening CHA capacity using a systems approach, their contributions can be aligned with national family planning goals such that they are considered essential partners in achieving universal access and reducing unmet need.

Further research is needed on the quality of family planning service provision within CHAs, the comparative contribution to family planning service delivery by the public sector and by CHAs, and the added value of engaging religious leaders in promoting healthy timing and spacing of pregnancy.

\section{Limitations}

The source of our family planning uptake data was program service statistics. Considering that providers were often overburdened and reporting structures were weak, such data was prone to errors. Data quality audits were conducted in select sites throughout the intervention, but the majority of data was not verified externally. We had to assume that program service statistics sufficiently reflected intervention results. Although providers at Caritas Rwanda and UCMB directed women who wanted to use a method that the site did not provide to a nearby facility, referral data was not collected. This should be strengthened in the future. 


\section{Conclusion}

In light of the present momentum to increase access to family planning through expanding options and engaging non-traditional partners, CHAs play an important role. There is significant untapped potential for family planning among CHAs. They can contribute to important increases in uptake when given a viable way to contribute to family planning goals. Fertility awareness methods offer a unique opportunity to encourage the participation of Catholic service delivery organizations in family plan-

\section{References}

1 Rutstein SO. Effects of preceding birth intervals on neonatal, infant and under-five years mortality and nutritional status in developing countries: evidence from the demographic and health surveys. Int. J. Gynaecol. Obstet 2005 Apr; 89(1): S7-S24. https://doi.org/10.1016\%2Fj. ijgo.2004.11.012

2 United Nations General Assembly [Internet]. Resolution 70/1. 2015. Transforming our world: the 2030 Agenda for Sustainable Development. Available from: http://www.un.org/ga/search/view_doc.asp?symbol=A/ RES/70/1\&Lang $=\mathrm{E}$

3 United Nations, Department of Economic and Social Affairs, Population Division. Trends in contraceptive use worldwide. New York (NY): United Nations; 2015. Available from: http://www.un.org/en/development/desa/ population/publications/pdf/family/trendsContraceptiveUse2015Report.pdf

4 Olivier J, Tsimpo C, Gemignani R, Shojo M, Coulombe H, Dimmock F, et al. Understanding the roles of faith-based health-care providers in Africa: review of the evidence with a focus on magnitude, reach, cost, and satisfaction. Lancet. 2015 Jul; 386(10005): 1765 - 1775. http://doi. org/10.1016/S0140-6736(15)60251-3

5 Campbell OM, Benova L, Macleod D, Goodman C, Footman K, Pereira AL, Lynch CA. Who, what, where: an analysis of private sector family planning provision in 57 low- and middle-income countries. Trop Med Int Health. 2015 Dec;20(12):1639-56. http://doi.org/10.1111/ tmi. 12597

6 Bardon-O'Fallon J. Availability of family planning services and quality of counseling by faith-based organizations: a three country comparative analysis. Reprod Health. 2017 14(57). https://doi.org/10.1186/s12978-017-0317-2

7 Wando L, Metzger A, Huber D, Brown J, Muwonge M. Family planning realities among faith-based medical ning, and they add to the choice of options women and couples receive from mixed-method settings. Accurate service delivery reporting in the HMIS is essential for documenting CHA contributions in family planning. Increased attention to strengthening and mainstreaming family planning service delivery across CHAs is imperative to meeting the Sustainable Development Goals, FP2020 goals, and improving the health of women and children.

bureaus in Uganda. Christian connections for international health; 2013. Available from: http://www.ccih.org/Family-Planning-Realities-Uganda.pdf

8 Tomkins A, Duff J, Fitzgibbon A, Karam A, Mills E, Minnings K, et al. Controversies in faith and health care. Lancet. 2015 Jul;386(10005): 1776 - 1785. http://doi. org/10.1016/S0140-6736(15)60252-5

9 Van Enk L, Wilson A, Jennings V. Faith-based organizations as partners in family planning: working together to improve family well-being. Washington (DC): Institute for Reproductive Health Georgetown University; 2011. Sponsored by USAID. Available from: http://irh.org/wp-content/ uploads/2013/04/IRH_Faith_Report.oct_.5.reduced.pdf

10 Duff J, Buckingham W. Strengthening of partnerships between the public sector and faith-based groups. Lancet. 2015 Jul; 386(10005): 1786 - 1794. http://doi.org/10.1016/ $\underline{\mathrm{S} 0140-6736(15) 60250-1}$

11 United Nations Population Fund. Culture Matters: lessons from a legacy of engaging faith-based organizations. New York (NY): United Nations Population Fund, 2008.

12 Pew Research Center Forum on Religious Life and Public Life. Tolerance and tension: Islam and Christianity in sub-Saharan Africa. Washington (DC): Pew Research Center, 2010. Available from: http://www.pewforum.org/ files/2010/04/sub-saharan-africa-full-report.pdf

13 Schmid B, Thomas E, Olivier J and Cochrane JR. The contribution of religious entities to health in sub-Saharan Africa. Study commissioned by Bill \& Melinda Gates Foundation. Unpublished report. African Religious Health Assets Programme (ARHAP), 2008. Available from: http:// www.irhap.uct.ac.za/irhap/research/pastprojects/healthcontribution

14 Arévalo M, Jennings V, Sinai I. Efficacy of a new method of family planning: the Standard Days Method ${ }^{\circledR}$. Contra- 
ception. 2002 May; 65(5):333-8. https://doi.org/10.1016/ $\underline{\mathrm{S} 0010-7824(02) 00288-3}$

15 Arévalo M1, Jennings V, Nikula M, Sinai I. Efficacy of the new TwoDay Method of family planning. Fertil Steril. 2004 Oct;82(4):885-92. https://doi.org/10.1016/j.fertnstert.2004.03.040

16 Labbok M, Hight-Laukaran V, Peterson A, Fletcher V, von Hertzen H. Multicenter study of the Lactational Amenorrhea Method (LAM): I. Efficacy, duration, and implications for clinical application. Contraception. 1997 Jun;55(6):327-36. https://doi.org/10.1016/S0010$\underline{\text { 7824(97)00040-1 }}$
17 Toth C. A powerful framework for women: introducing the Standard Days Method ${ }^{\circledR}$ to Muslim couples in Kinshasa. Washington (DC): Institute for Reproductive Health Georgetown University; 2011. Sponsored by USAID. Available from: http://irh.org/wp-content/uploads/2013/04/ FAMProjectReport_MamansAnSarDRC_FINAL.pdf

18 Family Health International. The Standard Days Method ${ }^{\circledR}$ in Kenya's Ijara District: final results and implications for programs. Nairobi: Family Health International; 2009. Available from: https://www.k4health.org/sites/ default/files/SDM $\% 20$ brief $\% 20$ KENYA $\% 20110609 \% 20$ \%281\%29.pdf

Peer Reviewed

Competing Interests: None declared.

Acknowledgements: The authors would like to thank Marie Mukabatsinda (IRH), Janet Komagum (UCMB), Judith Kiconco (UPMB), Bishop Dr. Anaclet Mwumvaneza (Caritas Rwanda), Agnes Icyizanye (Caritas Rwanda), and Christine Uwizeye (Caritas Rwanda) for their help on the implementation and evaluation of this intervention.

Correspondence: Laura VanEnk, Institute for Reproductive Health, Georgetown University. Lauren.VanEnk@georgetown.edu

Cite this article as: VanEnk $L$, et al. Closing the gap: The potential of Christian Health Associations in expanding access to family planning. Christian Journal for Global Health. July 2017; 4(2):53-65; https://doi.org/10.15566/cjgh.v4i2.164.

(C) VanEnk $L$ This is an open-access article distributed under the terms of the Creative Commons Attribution License, which permits unrestricted use, distribution, and reproduction in any medium, provided the original author and source are properly cited. To view a copy of the license, visit http://creativecommons.org/licenses/by/4.0/ 